\title{
Article \\ Evolutionary Maximization of Energy Amount Harvested by Means of Panel of Thermoelectric Modules
}

\author{
Tomasz Golonek (D)
}

Citation: Golonek, T. Evolutionary Maximization of Energy Amount

Harvested by Means of Panel of

Thermoelectric Modules. Appl. Sci. 2022, 12, 539. https://doi.org/ 10.3390/app12020539

Academic Editor: Yosoon Choi

Received: 16 November 2021

Accepted: 1 January 2022

Published: 6 January 2022

Publisher's Note: MDPI stays neutral with regard to jurisdictional claims in published maps and institutional affiliations.

Copyright: (C) 2022 by the author. Licensee MDPI, Basel, Switzerland. This article is an open access article distributed under the terms and conditions of the Creative Commons Attribution (CC BY) license (https:// creativecommons.org/licenses/by/ $4.0 /)$.
Department of Electronics, Electrical Engineering and Microelectronics, Silesian University of Technology, Akademicka 16, 44-100 Gliwice, Poland; tomasz.golonek@polsl.pl; Tel.: +48-32-2372297

Featured Application: Electric energy generation from renewable sources with efficiency optimization.

\begin{abstract}
This work proposes the use of a specialized algorithm based on evolutionary computation to the global MPPT regulation of panel of thermoelectric modules connected serially in numerous string sections. Each section of the thermovoltaic panel is equipped with local DC/DC converter controlled by the proposed algorithm and finally this allows the optimization of the total efficiency of conversion. Evolutionary computations adjust PWM signals of switching waveforms of DC/DC sectional simple boost converters, which have outputs configured in parallel. It gives the chance to obtain the highest level of electric energy harvested, i.e., thanks to boost converting operational points precise adaptation to the system temperature profile as well as electric load level. The simulation results of the proposed evolutionary technique confirmed the high speed of the MPPT process that is much better than for perturbation and observation, as well as incremental conductance methods, and it assures concurrent optimization of numerous PWM signals. Next, the work shows practical optimization results achieved by the proposed algorithm implemented to microcontroller module controlling the DC/DC converter during thermal to electric conversion experiment. A laboratory thermovoltaic panel was constructed from a string of Peltier modules and radiator that assured passive cooling. The measurements obtained once more proved the MPPT evolutionary regulation properness and its adaptation effectiveness for different resistive test loads.
\end{abstract}

Keywords: Seebeck effect; maximal power point tracking; evolutionary computation

\section{Introduction}

The natural environment protection is a crucial task of present times and this radically increases the importance of research in domains of electric energy clear production and its saving methods. Everybody wishes to have easy access to electric energy in any place and time, but conventional power plants cause unacceptable pollution and have limited efficiency as well as defined electric power production and distribution possibility. In this situation, the new techniques of wasted thermal energy harvesting and its conversion to the electric energy are very much desired. They may reduce the mentioned inconveniences and can be helpful in many areas, e.g., medicine [1,2], power supply to secluded places [3] or automotive related solutions [4-6].

Thermoelectric generators (TEGs) are modules which allow the conversion of thermal energy to the electric one in the direct way, i.e., without engaging any rotated elements, the ones present in conventional mechanical electro-generators, turbines, so this kind of system characterizes very high life cycle, guarantees maximal reliability, and, of course, assures electricity in any places with zero emission of additional pollution. The main disadvantage of the TEG system is its low efficiency of energy conversion and relatively high cost of installation, especially for lower temperatures [7]. On the other hand, a rising development of microelectronic technology and numerous studies on optimal utilization of 
matrices (panels) of TEGs [7-10] as well as TEG's cells being specifically constructed [11,12] should reduce the troubles pointed out here. The proposed work describes a thermoelectric generator constructed from less expensive, standard Peltier modules, typically applied as ones used for cool production. Due to the duality of Seebeck-Peltier phenomena, these converters can be successfully applied to the electric energy production too. It should be emphasized that the proposed solution assures the optimization of operational points of energy conversion in local string sections. The groups of thermoelectric (TE) modules are connected in series to increase the produced voltage before the boost operation by means of DC/DC converter. Duty cycle coefficients of waveforms which control switching transistors of simple local boost converters are, in the proposed system, determined by means of evolutionary computation. The implemented optimization algorithm is convergent on the square signals with pulse width modulation (PWM) levels which assure maximization of electric power generated from the panel of thermoelectric module strings. This specific maximal power point tracking (MPPT) algorithm corrects transistors switching cycles durations, respectively, to the changes of load condition and operational points of TEG module groups. References $[13,14]$ present a general review of the MPPT known techniques, in [15] an MPPT evolutionary technique that uses particle swarm optimization is proposed, however in [16] there is one applying a differential evolution computational method. It should be underlined that contrary to previously published works, which were depicted as evolutionary MPPT methods, the version proposed here allows the optimization of PWM signals duty cycles concurrently to all TE groups (strings) of global system. This unique feature makes possible the establishment of the thermovoltaic panel global optimum of operational point by respective trimming of local DC/DC converters operating points. Besides, specific procedure of fitness determination as well as original structure of chromosomes, dedicated method of population genetic recombination and its succession increase algorithm convergence speed significantly. The described evolutionary technique characterizes low computational cost and implementation capability to chip microcontroller module, which was confirmed by laboratory measurement results achieved in the practical example system.

Section 2 contains basic information about thermoelectric modules, and explains the rule of electric current generation and device limitations. In Section 3, a detailed description of the proposed solution of multistring thermoelectric panel with MPPT evolutionary regulation is presented. Next, a simulation experiment is described in Section 4 and convergence correctness and computation time of the proposed technique are tested. Then, the laboratory-constructed panel and practically achieved measurements are placed in Section 5. Final discussion and conclusions may be found in the last section.

\section{Thermoelectric Module}

The structure of thermoelectric converter module is illustrated in Figure 1. It consists of several dozen semiconductor N-P junctions electrically connected in series. Temperature gradient on opposite ceramic plates of the module causes valence electrons movement from the hotter to the colder side, generating pairs of electron-hole that affect electric current flow in a load circuit. Respectively to the Seebeck's phenomena, inner electric field produced on the semiconductor junction as well as voltage on module terminals are proportional to temperature difference $T_{H}-T_{C}$ established between layers of oppositely doped materials. The figure of merit of thermoelectric module can be defined as $[17,18]$ :

$$
\mathrm{ZT}=\alpha^{2} \frac{T}{\rho \lambda},
$$

where $\alpha, \rho$ and $\lambda$ are Seebeck coefficient, electrical resistivity and thermal conductivity, respectively, parameters specific to connected materials which are assured under average operation temperature point $T$. The presence of electrical resistivity causes Joule heat energy dissipation on the inner resistance of the device and it requires MPPT algorithms usage for this inescapable energy loss minimization. However, thermal conductivity $\lambda$ existing 
between opposite sides of module ceramic plates strongly limits temperature distance $T_{H}-T_{C}$ available for a real device with small thickness of few millimeters typically. Heat energy is transferred between converter sides and this results in temperature gradient degradation. Theoretical efficiency of thermoelectric module is associated directly with the Carnot principle and is formulated as $[17,18]$ :

$$
\eta=\left(1-\frac{T_{C}}{T_{H}}\right) \frac{\sqrt{1+Z T}-1}{\sqrt{1+Z T}-\frac{T_{C}}{T_{H}}},
$$

so electrical energy obtained strongly depends on thermal isolation achievable for assuring possible temperature difference between thermoelement ceramic sides. Maximal efficiency of currently available thermoelectric devices reaches about $15 \%$ which was obtained for a module constructed from skutterudite materials operated at $T_{H}-T_{C}=200{ }^{\circ} \mathrm{C}$ temperature gradient [12]. As may be concluded, relatively low efficiency and considerable production cost of thermoelectric generator modules are still main bottlenecks $[19,20]$. It limits the wide offer possibility of this kind of panel, but the situation described should change due to intensive microtechnology [21] and new materials dominate research explorations [20-22], i.e., similarly as was observed previously for PV panels. On the other side, the crucial pros of thermoelectric modules are their durability and reliability guaranteed by thermal to electric conversion without any movement of mechanical elements and possibility of electric energy production in secluded places where application of another electricity source is impossible (e.g., space equipment). Besides, low power thermo-electric conversion is possible just now, i.e., with acceptable cost of TEG low-sized installation heated autonomically from thermal energy often wasted in exothermic processes (e.g., to automotive sensors wireless supply).

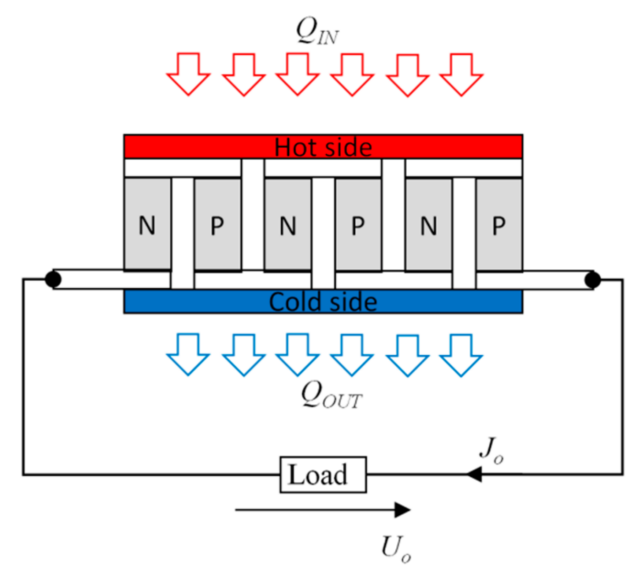

Figure 1. Thermoelectric module structure.

\section{Thermoelectric Panel with Evolutionary MPPT}

As was pointed out in the previous section, the presence of internal resistances of TE modules causes undesired energy loss during the conversion process. This Joule heat dissipated on devices may be minimized by match optimization of electric load to source of TE modules connected in series in local groups. For example in $[13,14,23,24]$ the descriptions of perturbation and observation, increment conductance, constant voltage and fractional open-circuit voltage MPPT methods are presented. However, papers [25-28] propose alternative MPPT techniques by means of artificial computational intelligence methods.

The solution proposed in this work is based on evolutionary computations, which imitate natural processes of rivalry in population of individuals [29]. This optimization methods may be used to solve many kinds of difficult tasks, and exemplary applications are: analog electronic circuits testing and diagnosing with elements' tolerance dispersion presence [30,31] or image processing with pixel noise presence [32]. These referenced papers propose the usage of different kinds of evolutionary algorithm (EA) but five common stages 
of evolutionary computations are: individuals (chromosomes or genotypes) quality (fitness) determination, mating (reproducing) pool selection with assumed pressure, genetic material (code created from alleles) recombination, random mutation and succession of offspring generation. The fundamental issue of EA application to the considered task is adequate designing of code structure of individuals and respective formulation of fitness function and genetic operations. They should guarantee the desired speed of heuristic probing of searching space. All the elements of EA application to MPPT mentioned here are described in detail in the next subsection, however the idea of the proposed MPPs evolutionary tracking in serially connected local strings of thermoelectric modules is illustrated in Figure 2. This is an example panel which consists of four sections $(N=4)$ of modules controlled individually and the proposed idea can be easily extended to larger installations. Each local string consists of a dedicated DC/DC simple converter with regulated voltage gain that makes it possible to track the optimal operational point of individual string of TEGs. Control signals $x_{c 1}(t), \ldots, x_{c N}(t)$ decide about conversion points of DC/DC block in the dedicated section and they are square waveforms with duty cycles determined evolutionarily to levels allowing harvest of the maximal electric power from specific string of panel modules. These signals decide the voltage gains of particular boost converters and allow to adapt them to the current conditions of system electric load and thermal profile present on the panel. The evolutionary optimization proceeds among local devices and this makes it possible to effectively investigate the optimal operating point of each group and results in the total electric energy produced maximization. Besides, the proposed multi-strings/multi-converters dispersed structure from Figure 2 assures relatively small levels of electric currents of local low power boost converters and this should proceed with higher total efficiency than for a single common converter processing the whole power of the panel.

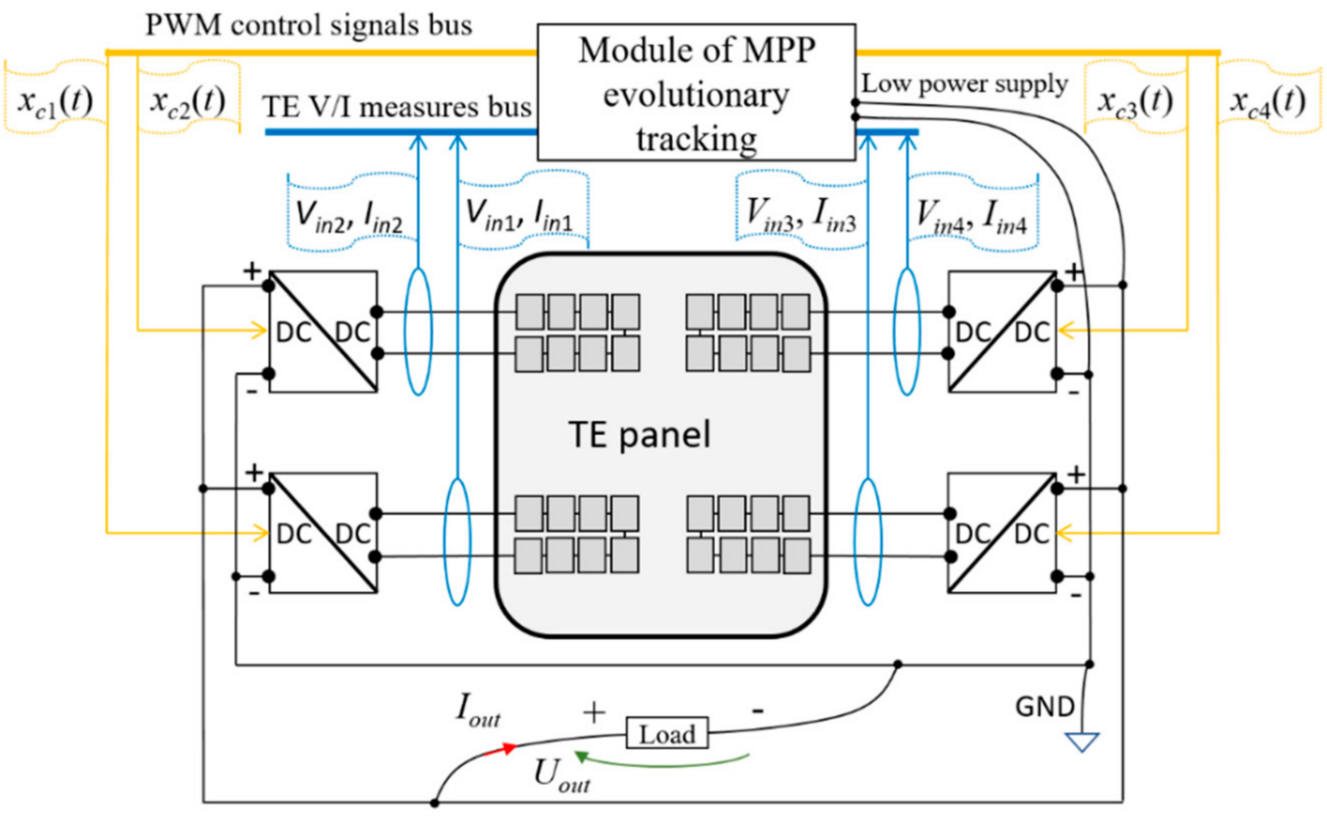

Figure 2. TE panel with the individual mini-converter in each section.

\subsection{Evolutionary MPPT Algorithm Description}

Steps of the evolutionary optimization are collected in an algorithm diagram presented in Figure 3. This original solution is designed for the considered optimization task. In particular, the proposed technique allows to simultaneously search for all control signals duty factors of string sections of the thermovoltaic panel. Below, the details explaining operations and population structure specific for MPPT evolutionary system are presented. 


\section{MPPT start:}

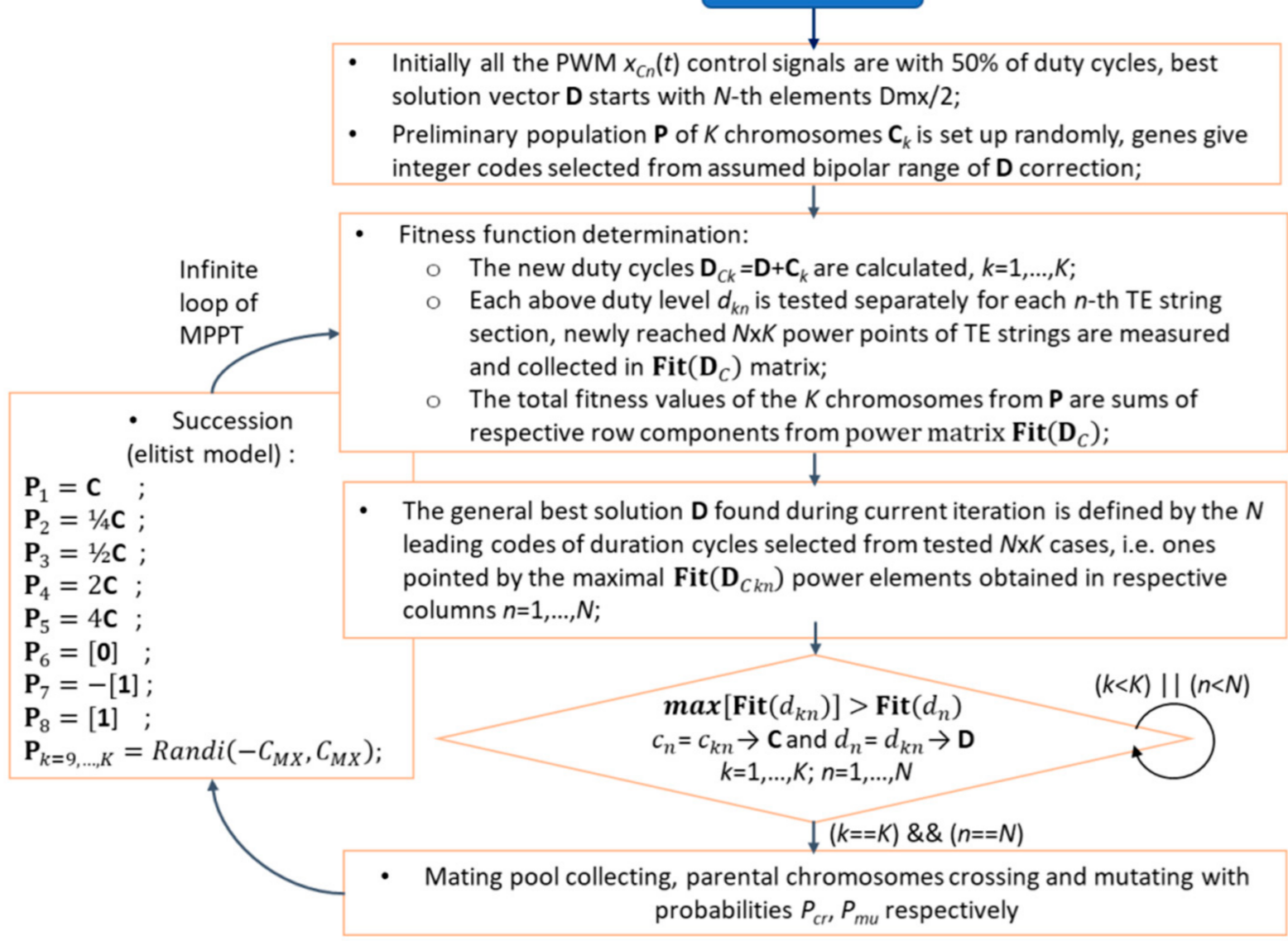

Figure 3. The proposed MPPT evolutionary method diagram.

The proposed application of EA allows to effectively search for the vector $\mathbf{D}$ of $\mathrm{N}$-th most suitable coefficients $d_{1}, d_{2}, \ldots, d_{N}$ of duty cycles for DC/DC converters of particular TE strings:

$$
\mathbf{D}=\left[\begin{array}{llll}
d_{1} & d_{2} & \cdots & d_{N}
\end{array}\right] .
$$

The population of $K$-th chromosomes (individuals) consists of correction coefficients vectors containing deviations of the currently operated $\mathbf{D}$, which may assure the best MPP matching:

$$
\mathbf{P}=\left[\begin{array}{c}
\mathbf{C}_{1} \\
\mathbf{C}_{2} \\
\vdots \\
\mathbf{C}_{K}
\end{array}\right]=\left[\begin{array}{lllll} 
& c_{11} & c_{12} & \cdots & c_{1 N} \\
& c_{21} & c_{22} & \cdots & c_{2 N} \\
& & & \vdots & \\
& c_{K 1} & c_{I 2} & \cdots & c_{K N}
\end{array}\right] .
$$

Initially, after the first execution of the algorithm, all the operational points (3) of TE panel are set up to the middle positions $D_{M X} / 2\left(50 \%\right.$ of all the control signals $x_{n}(t)$ duty cycles), i.e., defined by the assumed regulation resolution of $D_{M X}$ discrete decimal levels. The quality of this preliminary operational point of the panel is determined. The fitness value of the system is the sum of electric powers received from all the particular TE strings for the vector $\mathbf{D}$ of the tested duty cycles $d_{n}$ :

$$
F i t(\mathbf{D})=V_{i n 1}\left(d_{1}\right) I_{i n 1}\left(d_{1}\right)+V_{i n 2}\left(d_{2}\right) I_{i n 2}\left(d_{2}\right)+\cdots+V_{i n N}\left(d_{N}\right) I_{i n N}\left(d_{N}\right),
$$

where $V_{i n n}$ and $I_{i n n}$ are voltage and current registered on the input port of the the $n$-th $\mathrm{DC} / \mathrm{DC}$ converter when $d_{n}$ of control signal $x_{n}(t)$ is established. The vector $\mathrm{C}$ of the best 
corrections coefficients applied during last iteration is zeroed during the begin stage of the algorithm:

$$
\mathbf{C}=\left[\begin{array}{llll}
c_{1} & c_{2} & \cdots & c_{N}
\end{array}\right]=[0] .
$$

However, preliminary population $\mathbf{P}$ is initialized by $I$ candidates selected randomly from the allowed range $\left\langle-C_{M X}, \ldots, 0, . ., C_{M X}\right\rangle$ dedicated for each respective coefficient $d_{n}$ correction, i.e., lying on the same position $(n=1, \ldots, N)$ in chromosome $\mathbf{D}$. The main loop of evolutionary optimization starts and the new potential duty cycle levels are checked, i.e., the ones obtained for the duty cycles (3) corrected with respective row vector coded in population (4):

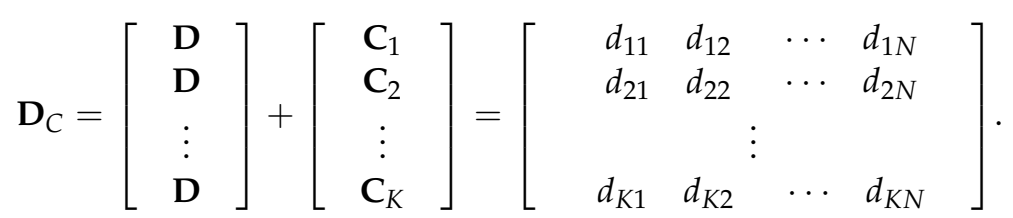

In the firmware implemented, the fitness marks assured by corrected duties (7) are calculated among $N$-th regulation vectors individually for each TE section and full matrix of electric power components is determined:

$$
\boldsymbol{F i t}\left(\mathbf{D}_{C}\right)=\left[\begin{array}{cccc}
V_{i n 1}\left(d_{11}\right) I_{i n 1}\left(d_{11}\right) & V_{i n 2}\left(d_{12}\right) I_{i n 2}\left(d_{12}\right) & \cdots & V_{i n N}\left(d_{1 N}\right) I_{i n N}\left(d_{1 N}\right) \\
V_{i n 1}\left(d_{21}\right) I_{i n 1}\left(d_{21}\right) & V_{i n 2}\left(d_{22}\right) I_{i n 2}\left(d_{22}\right) & \cdots & V_{i n N}\left(d_{2 N}\right) I_{i n N}\left(d_{2 N}\right) \\
\vdots & \vdots & & \\
V_{i n 1}\left(d_{11}\right) I_{i n 1}\left(d_{11}\right) & V_{i n 2}\left(d_{K 2}\right) I_{i n 2}\left(d_{K 2}\right) & \cdots & V_{i n N}\left(d_{K N}\right) I_{i n N}\left(d_{K N}\right)
\end{array}\right]
$$

Next, the newly reached fitness levels, i.e., guaranteed after corrections coded in chromosome genes are sums of all the respective rows components of matrix (8), as is shown in (6). However, the best solution $\mathbf{D}$ found during the generation cycle is the one defined by the highest $N$ power components selected from particular columns of (8), i.e., one which assures the maximal value of total sum (MPP). The best corrections vector $\mathrm{C}$ is updated by deviations detected as the most desired ones, i.e., assuring maximal total progress of electric power sourced from TEs:

$$
\begin{aligned}
& \forall \\
& k=1, \ldots, K \quad \exists\left[\boldsymbol{F i t}\left(d_{C k n}\right)>\operatorname{Fit}\left(d_{n}\right)\right] \rightarrow\left[c_{n}=c_{k n} \text { and } d_{n}=d_{C k n}\right] . \\
& n=1, \ldots, N
\end{aligned}
$$

This method of fitness determination is powerful, gives a very efficient sampling of solution space by $K \times N$ tests points and affects with very high convergence the speed of the algorithm.

The next steps of the evolutionary optimization algorithm are run with the mating pool that is collected from chromosomes of the current population. Chromosomes reproduction in the mating pool depends on their fitness levels; the ones evaluated better have a higher chance to distribute genes code and inherit them by offspring individuals. This mechanism imitates natural selection phenomena and causes reproduction pressure corelated with the quality of candidates [29]. Genetic material is exchanged during crossover operation executed on pairs from the parent pool and starts typically with relatively high probability $P_{c r}$ assumed for iteration. The last operation that has influence on children strings is the mutation that randomly degrades selected genes with relatively small probability $P_{m u}$. A detailed explanation of genetic operations mentioned here is placed in the next subsection.

After the $K$ child chromosomes creation, the new offspring population is ready and this succeeds the previous generation. The proposed algorithm main loop is closed and fitness levels (6) are determined for the chromosomes newly obtained (corrected) and detailed components for offspring genes are collected (8). The described cycle is repeated within the infinite loop of implemented firmware, and due to selection pressure, chromosomes with 
the highest quality (i.e., coding the best duty cycles of PWM signals) dominate among next generations and they define actual adjustments for MPP efficient tracking.

\subsection{Genetic Operations}

During the genetic material recombination process, better fitted individuals are preferred, so the reproduction (mating) pool is collected respectively to their qualities. Initially, chromosomes are sorted, respectively, to achieved fitness values (represent power point received) in descending order. This means that the one with currently the best phenotype is the first one in this queue (obtains rank 1, i.e., the highest in the population), while the code of the worst phenotype is ordered as the last one (i.e., with $K$ rank, integer number equal to population size). Next, the mating pool is completed randomly with success selection when the below formula is fulfilled:

$$
\left[P_{m n}+\left(1-P_{m n}\right) \frac{K-r}{K}\right]>\operatorname{Rand}(1),
$$

where $P_{m n}$ is minimal probability assumed for selection (this parameter regulates selection pressure, gives chance to worse chromosomes to be recombined too, protects before algorithm stagnation at local optimums) and $r$ means the rank of a candidate.

After parental pool determination, the pairs of $k_{1}$-th and $k_{2}$-th chromosomes are pointed randomly among them $\left(k_{1}, k_{2}=1, \ldots, K\right)$ and crossover procedure is started. The proposed evolutionary system uses weighted sum to calculate resultant, recombined $n$-th gene $(n=1, \ldots, N)$ from the formula:

$$
\ddot{c_{n}}=\frac{F i t\left(\mathbf{D}+C_{k 1}\right)}{\operatorname{Fit}\left(\mathbf{D}+C_{k 1}\right)+F i t\left(\mathbf{D}+C_{k 2}\right)} c_{k 1 n}+\frac{F i t\left(\mathbf{D}+C_{k 2}\right)}{\operatorname{Fit}\left(\mathbf{D}+C_{k 1}\right)+F i t\left(\mathbf{D}+C_{k 2}\right)} c_{k 2 n},
$$

where $c_{k 1 n}, c_{k 2 n}$ are parental genes (decimal values coding $n$-th channel duty cycle correction), $\operatorname{Fit}\left(\mathbf{D}+\boldsymbol{C}_{k 1}\right), \operatorname{Fit}\left(\mathbf{D}+\boldsymbol{C}_{k 2}\right)$ mean fitness values reached for respective parents (power points (6) obtained after correction). This crossover scheme is executed on the selected pairs with probability $P_{c r}$ (the same copies are preserved otherwise) and the proposed recombination scheme allows to inherit a significant part of leading chromosome genes that is spreading to next generations.

Fully random degradation of genetic material is called mutation and for the proposed system it is a simple replacing of genes pointed with small probability $P_{m u}$ by a completely new integer number uniformly chosen from the allowed range $\left\langle-C_{M X}, \ldots, 0, . ., C_{M X}\right\rangle$. The goal of this operation is to make testing of solutions different from the dominating one available and it is especially important e.g., when TE system load rapidly changes (MPP should be searched on another part of solutions space).

Finally, after the described recombination steps, offspring chromosomes are ready to proceed into the next generation. For the specific problem of MPPT, a special succession technique is applied and this may be seen in Figure 3 diagram. The first eight chromosomes of the newly created population are constructed from a subset of specialized individuals:

$$
\left[\mathbf{P}_{1}, \ldots, \mathbf{P}_{8}\right]=[\mathbf{C}, \mathbf{C}, \mathbf{C}, 2 \mathbf{C}, 4 \mathbf{C}, 0,-1,1],
$$

which are the last vector of the best corrections found and vectors created from the fourth, half of them as well as the two and the four times of them. Additionally, there are the zeroed vector and fully completed ones with decimal -1 or 1 , and they assure previously found power point preservation, minimal (one step) decreasing or increasing of duty cycles, respectively. This solution gives a chance to efficiently test corrections of vector D by currently the best vector $\mathbf{C}$ (elitist model) and makes possible its keeping or local adjusting (i.e., down or up, with the system counter resolution maximal preciseness). The evolutionary controlled MPPT algorithm explained was tested by means of simulation and practical experiments described in the next two sections. 


\section{Simulation Experiment}

The proposed algorithm of evolutionary MPPT as well as standard, widely known, called perturbation and observation (P\&O) and incremental conductance (INC) methods $[13,14,23,24]$ were implemented in a Matlab environment. These three techniques were used to search for the optimal duty cycles of boost converter (Figure 4a) signals which control MOSFET transistor switching (Figure $4 b$ ) in $N=10$ boost converter sections with MPP defined by different matching curves from Figure $4 c$. This example normalized functions of load resistance $R_{0}=100 \Omega$ power dissipated vs. duty cycle of switching signal were established for internal resistances $R_{i}$ selected from the range $(10,100) \Omega$. As it may be noticed, the maximal point strongly depends on sourcing circuits parameters and it is possible to track this optimum by means of duty cycle of switching signal regulation.
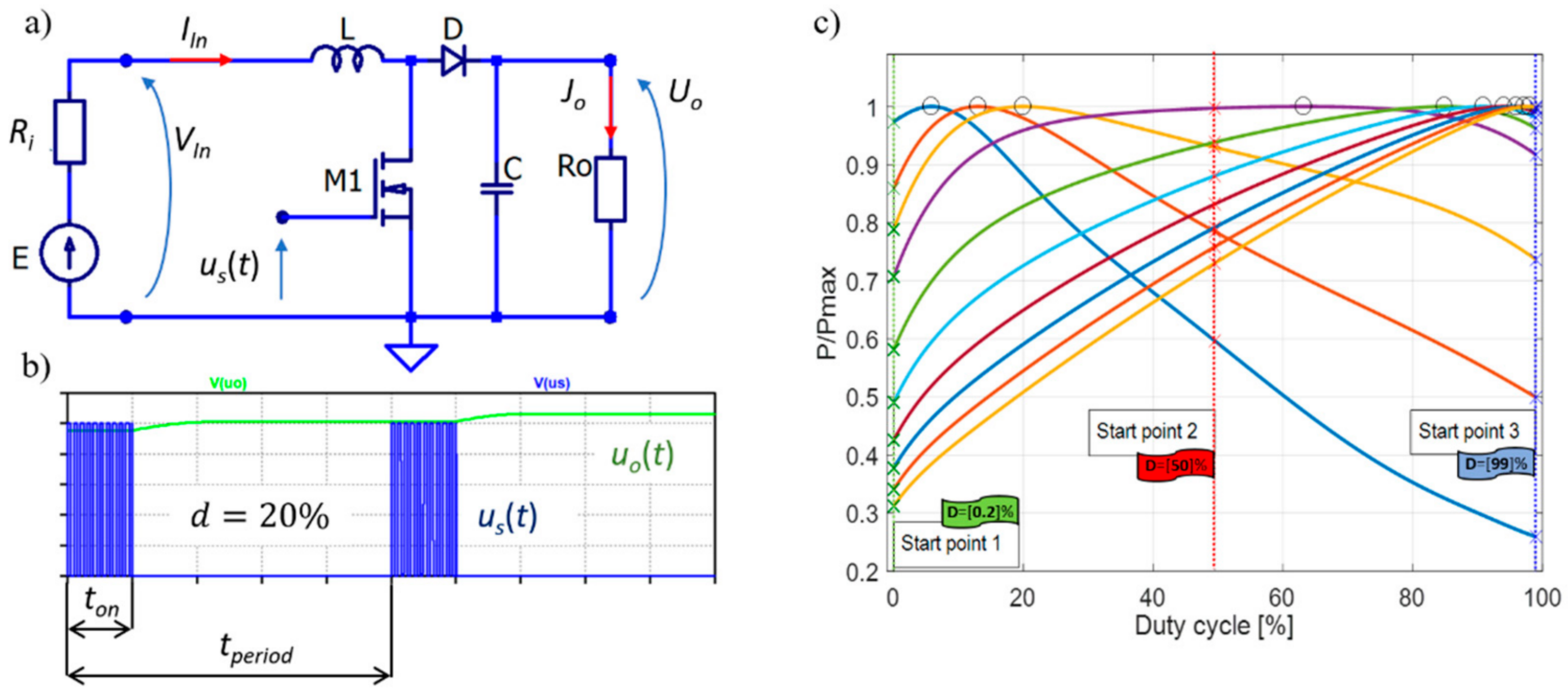

Figure 4. Simulation verification: (a) analyzed boost topology, (b) example signal controlling output voltage, (c) normalized load power vs. transistor gate signal duty cycle matching curves.

The three completely different starting points were assumed for tests and are cross denoted in Figure 4c (sets of start points 1, 2 and 3). The initial duty cycles assumed for MPPT methods competing during tests are the same and are placed at: minimum, medium and maximum for all the optimized control signals of boost converters (i.e., at $0.2 \%, 50 \%$ and $99 \%$ of duty cycles, respectively). The proposed locations of coefficients of duty cycles start vector $\mathbf{D}$ allow to test the competitive algorithms convergence speed from the initial points differently far from global optimum. Optimization was started for $D_{M X}=10,000$ discrete levels that means resolution $\Delta d=0.01 \%$ of duty cycle adjusting preciseness, identical for all tested methods. Initial parameters assumed for evolutionary system were: size of population $K=20$ chromosomes; allowed maximal correction for one iteration $C_{M X}=1000$; minimal chance for reproduction $P_{m n}=0.2$; crossover and mutation probabilities $P_{c r}=0.9$ and $P_{m u}=0.2$, respectively.

The computational effectiveness for the described tests is shown in Figure 5, where the time quality progresses of the proposed evolutionary and classical approaches are presented (time vs. the best phenotype normalized fitness values). For each considered case, the proposed MPPT algorithm found the best solution up to $t_{m x 1} \approx 30 \mathrm{~ms}$, however the $\mathrm{P} \& \mathrm{O}$ algorithm needs $t_{m x 1} \approx 430 \mathrm{~ms}$ maximally and very similar time cost in the case of INC approach (for the same tasks, on the same PC machine). This means about 14 times faster convergence of the proposed evolutionary MPPT method. 


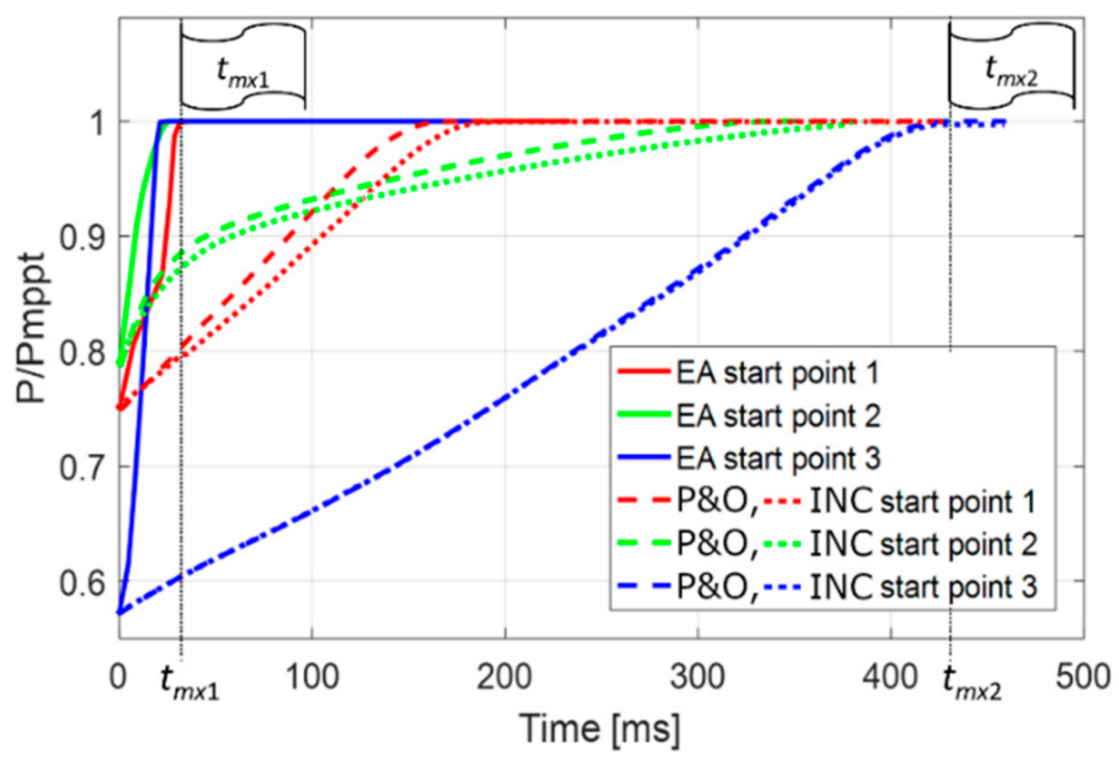

Figure 5. Convergence speed of the compared methods.

Besides, Figure 6 illustrates a normalized level of average fitness value spreading among generations. As may be seen, the initial, poor levels of the phenotypes qualities grow rapidly and stabilize after about $50 \mathrm{~ms}$. This tendency proves high convergence speed of the proposed algorithm that probes solution space in many points defined by chromosome codes. It is worth noticing that when the best solution is found (i.e., after $t_{m x 1} \approx 30 \mathrm{~ms}$ ), average quality of population varies a little, too. This means that MPP is tracked (tested) still and in case of operational point of the TE system changes, the newly located optimum will be searched and found again. This is the effect of generations successions made in a specific way explained in Section 3.2 as well as genes mutations run during the main infinite loop of the evolutionary algorithm. Finally, thanks to a very high mean measure of electric power transferred to the system load, this system will assure very good total effectiveness of thermal- to electric-energy conversion.

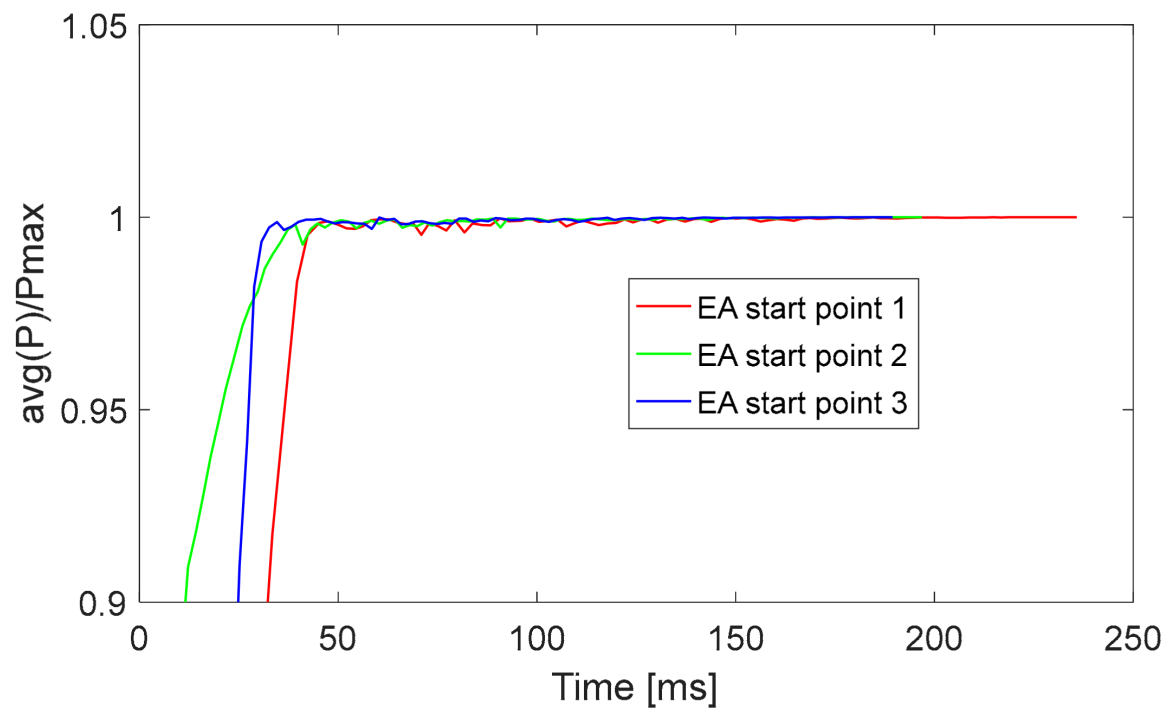

Figure 6. Average fitness into population progress curves.

\section{Practical Experiment}

The correctness of MPPT regulation by means of the described evolutionary method was tested practically and the results from one string of 16 relatively low-cost TES1-24106 
modules (dimensioned as $40 \times 40 \times 2.8 \mathrm{~mm}$ ) connected in series are presented in this section. The electric diagram of boost converter used during this experiment is presented in Figure 7. A simple joule thief, a supercharged version of self-powered and self-oscillating boost converter topology is chosen for local MPPT low power processing. This self-oscillating circuit is cheap for realization, assures start for a low supply voltage [33-35] and after a small modification may be useful for the sectional optimal power point tracking by NMOS M1 PWM switching signal respective adjusting. An evolutionary system was implemented to STM32L476 firmware and the complete laboratory test station assembled is shown in Figure 8.

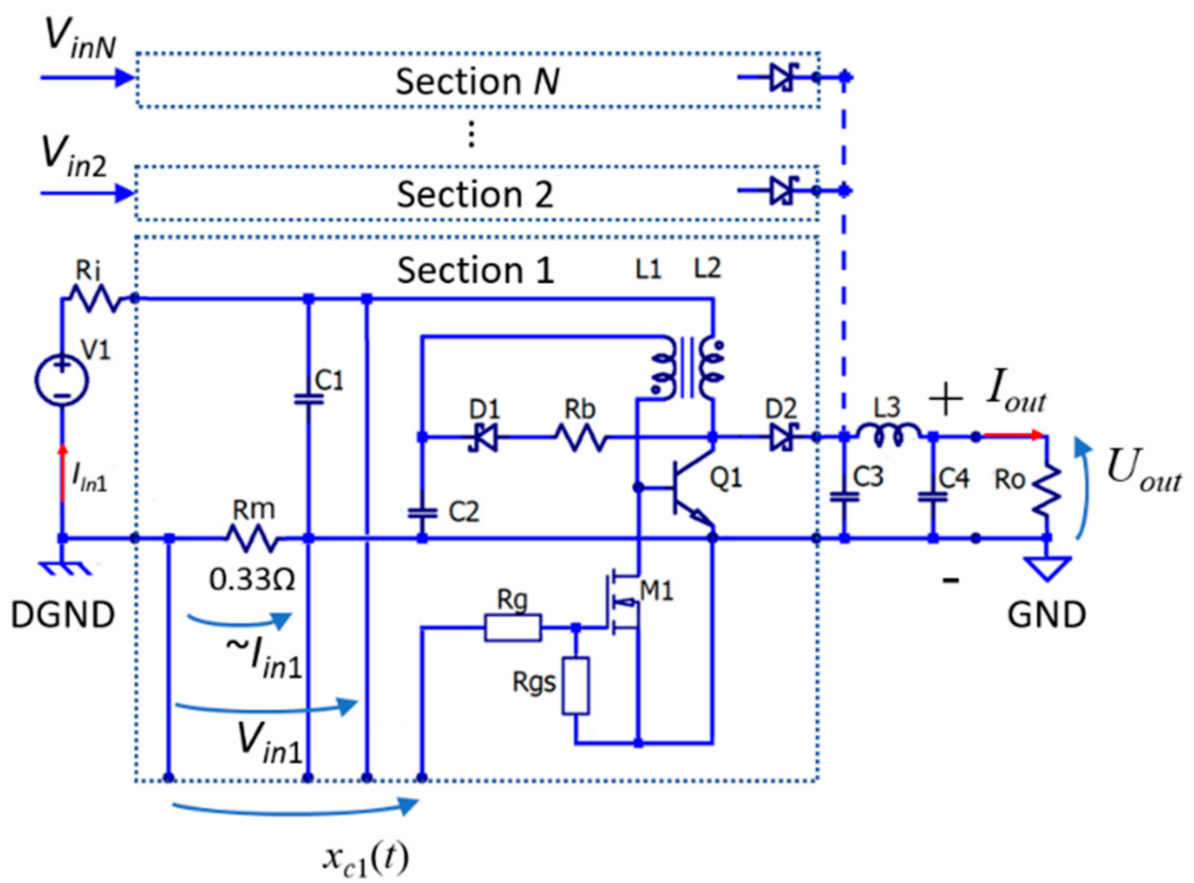

Figure 7. Electric diagram with simple boost converter dedicated to each TE string.

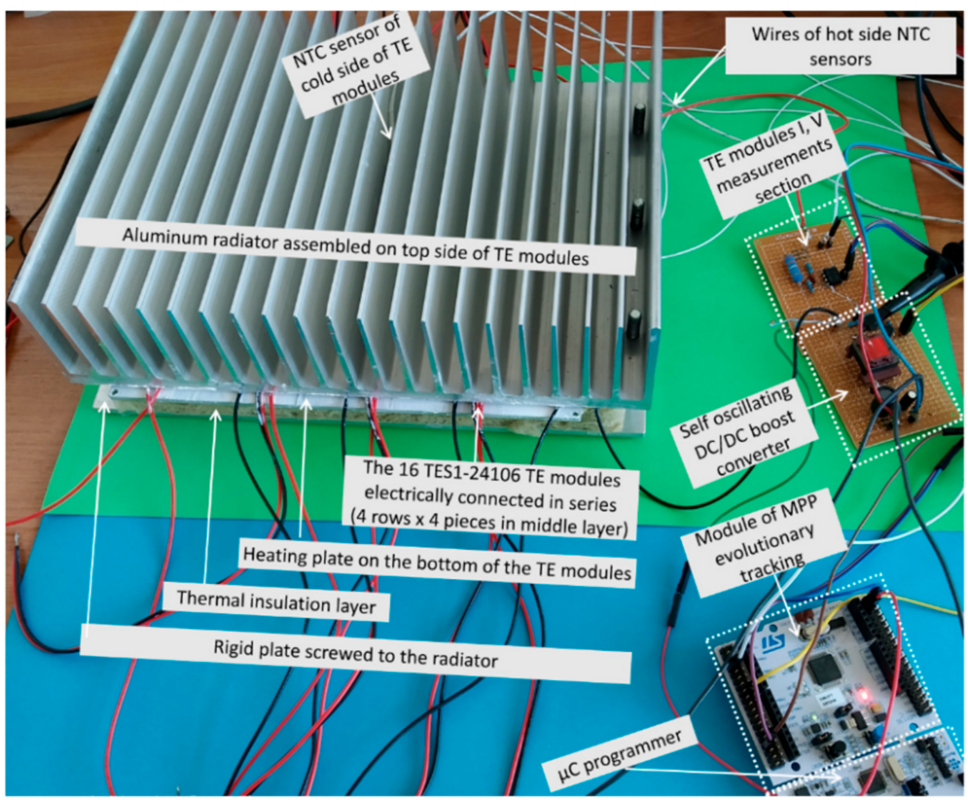

Figure 8. The laboratory test station of TE panel with passive cooling. 
The 16 TES1-24106 modules are placed in four rows between a heating plate and aluminum radiator that assures passive cooling of the TE panel low temperature side by means of surrounding air convection. This cooling method is not quite effective, but any power supply and additional mechanical, moving components are not needed there. Silicon thermo paste is applied on both ceramic sides of each TE devices and together with heating surface they are pressed mechanically to the radiator by means of a few springs and bottom rigid plate screwed on. Additionally, on the hot side there is thermo-isolation rock wool layer reducing undesired energy dissipation to the air. The matching power curve obtained for the constructed TE panel is presented in Figure 9.

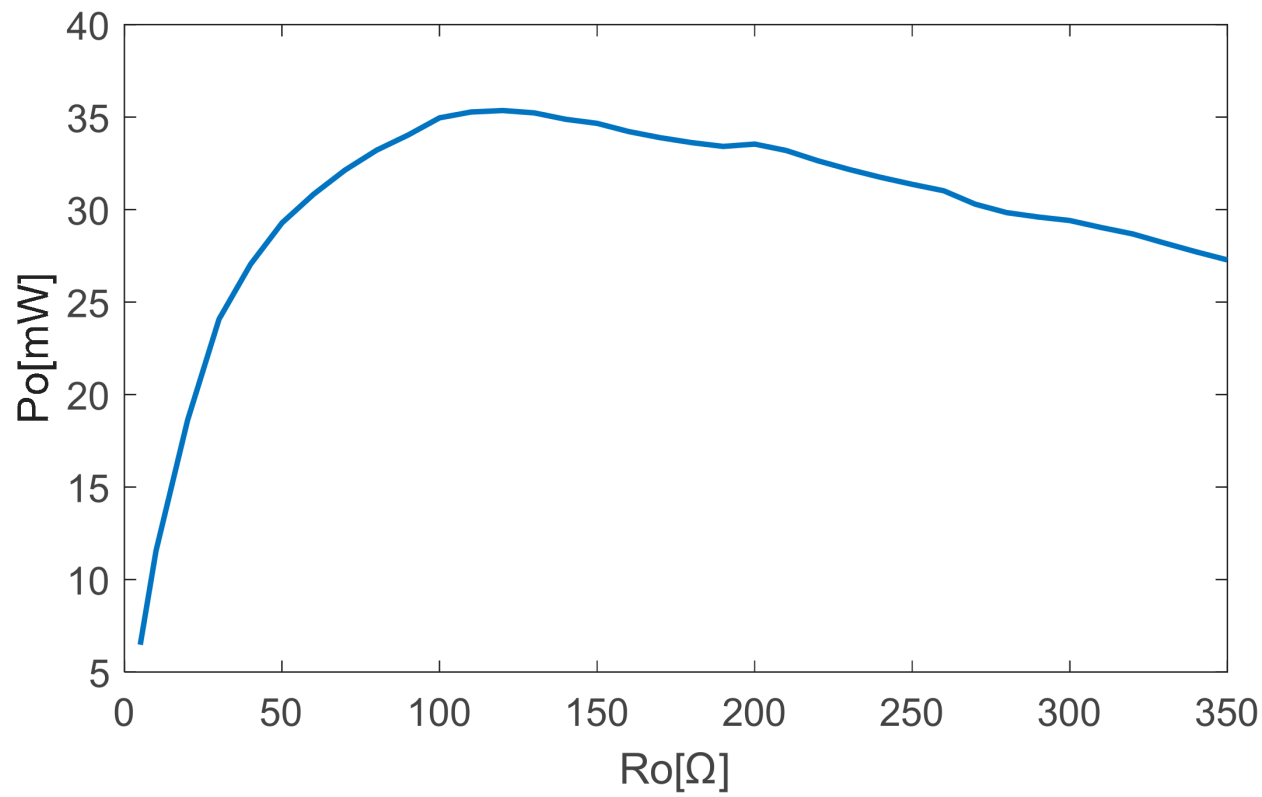

Figure 9. The power matching curve measured for the tested TE panel underside.

The above curve presents the relationship between output power $P_{o}$ delivered and load resistance $R_{o}$ for temperature difference $T_{H}-T_{C} \approx 5{ }^{\circ} \mathrm{C}$ and $40{ }^{\circ} \mathrm{C}$ on the hot side. As it may be noticed, for the assumed temperature point, the match resistance is about $R_{M P P T}=120 \Omega$ and the microcontroller should operate with PWM signal assuring the operation of energies converting possibly close to this optimal load level.

Low power boost converter and TE modules string output current-voltage measurement block are presented in Figure 8 on the right side of the panel and they are connected to the evaluation board equipped with ultra-low power ARM microcontroller family STM32L4 that accepts a wide range of 1.71-3.6 V of voltage supply and consumes just $100 \mu \mathrm{A} / \mathrm{MHz}$ during run mode. The STM32L476 chip has the three embedded 12 bits A/D converters and offers up to the seven internal counters that allows it to generate PWM signals on output terminals (more than 20 independent channels available for the $N=20$ TE strings individual controlling).

The tested evolutionary method was implemented to microcontroller and run with system clock $f_{C L K}=48 \mathrm{MHz}$, ADC sampling frequency $f_{S} \approx 50 \mathrm{kHz}$ and $D_{M X}=16,000$ discrete levels available for duty cycle settings. The optimized square signal generated by counter TIM1 had a frequency of $f_{P W M}=3 \mathrm{kHz}$ with impulses durations evolutionarily determined in the way described in Section 3. Evolutionary computations were started for initial parameters: population size $K=20$; one controlled channel $N=1$; maximal steps of one iteration $C_{M X}=1000$; and genetic operations probabilities $P_{m n}=0.2, P_{c r}=0.9, P_{m u}=0.2$, respectively. The evolutionary MPPT results may be observed in Figure 10. There are records of measurements of the temperatures: on the hot side $T_{H}$, the cold side $T_{C}$ and their difference value $\Delta T$ as well as voltage on boost converter output with the evolutionary MPPT optimization up to $1 \mathrm{~min}\left(x_{c 1}(t)\right.$ PWM regulated) and without it after this time 
$\left(x_{c 1}(t)\right.$ zeroed, continuous oscillations of converter). These measurements are achieved for a steady state of thermal transfer in the tested TE system. The temperatures on the hot and cold sides of TE devices have relatively low variations and they fluctuate in narrow ranges $\left(67^{\circ} \mathrm{C}, 72^{\circ} \mathrm{C}\right)$ and $\left(56^{\circ} \mathrm{C}, 59^{\circ} \mathrm{C}\right)$ approximately. The mean value of temperature difference $\Delta T$ is close to $12^{\circ} \mathrm{C}$.
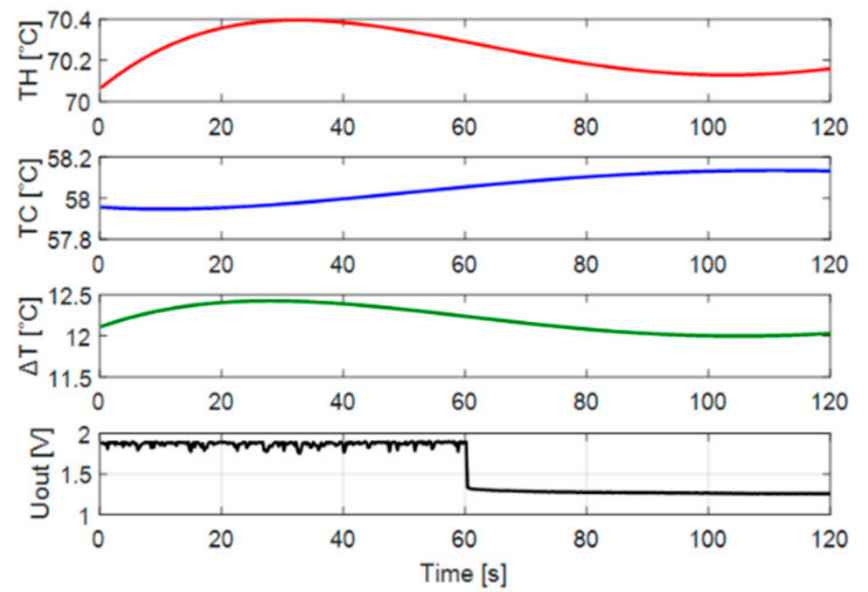

(a)
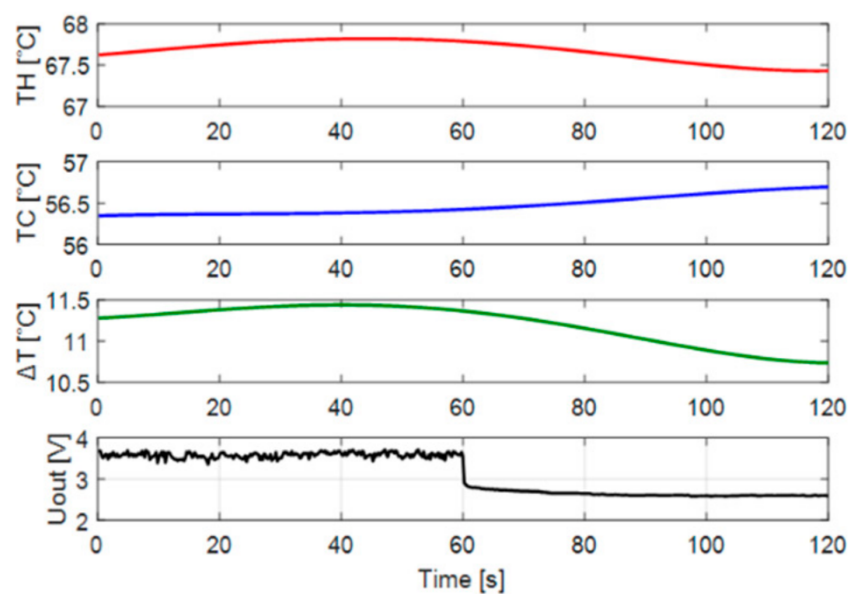

(c)
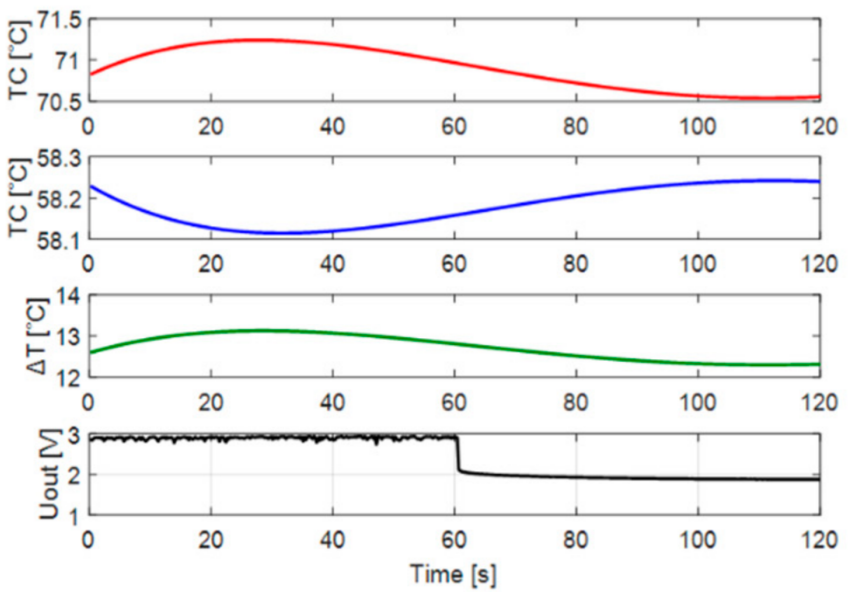

(b)
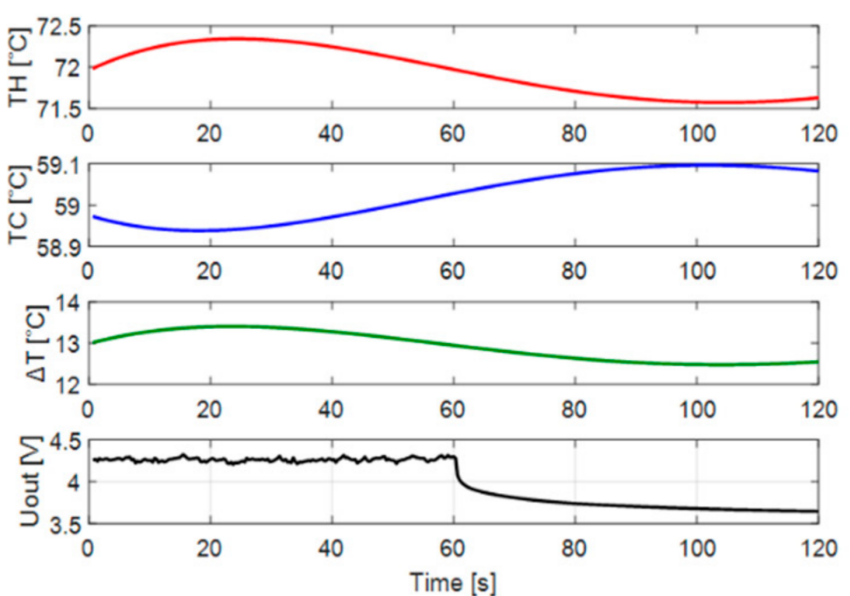

(d)

Figure 10. The temperatures and DC/DC converter output voltage curves up to minute obtained with MPPT stopped after 1 min for loads: (a) $R_{o}=50 \Omega$, (b) $R_{o}=100 \Omega$, (c) $R_{o}=200 \Omega$, (d) $R_{o}=500 \Omega$.

The measurements (a), ..., (d) of the above sets of figures were obtained for the resistive loads $R_{o}=50 \Omega, R_{o}=100 \Omega, R_{o}=200 \Omega, R_{o}=500 \Omega$, respectively. As was expected, the load voltage $U_{\text {out }}$ is higher when MPP is tracked evolutionarily (i.e., for the first $1 \mathrm{~min}$ of this experiment). This procedure allows to maximize the TE panel total efficiency and the MPP may be investigated precisely in individual string sections by means of single low power microcontroller system and effective tracking algorithm. It is worth noticing in Figure 10 that the temperatures difference $\Delta T$ (approximated curve) decreases when MPPT algorithm is disabled (i.e., always after $1 \mathrm{~min}$ from beginning the experiment). This specific effect proved conversion efficiency improvement assured by the proposed algorithm, i.e., Joule heat energy lost on the inner resistance of TE is higher for non-optimized stages and this causes $T_{H}-T_{C}$ gradient degradation. Besides, an evolutionary searching is active all the time and results in local deviations of resultant voltage $U_{\text {out }}$, however its average level is near to the optimal one. This local probing of MPP search space (duty cycles regulations in the area defined by $C_{M X}$ ) guarantees improved local tracking as well as expected reactions 
in case of load points changes. In effect, the optimal thermal to electric energy operational point of transformation is rapidly corrected if necessary.

The electrical powers achieved for evolutionarily optimized MPP as well as the ones for boost continuous conversion are collected in Table 1 . The experiment results prove that the proposed MPPT algorithm assures significant minimization of loss of energy dissipated on the internal parasitic resistances of thermoelements. For the two out of four cases considered here, the power produced after optimization (the PWM control activated) is twice higher than without it (i.e., for converter continuous oscillations). Of course, the range of optimal point tracking is limited by performances of simple boost converter used and for $R_{o}=500 \Omega$ the power produced progress is close to $25 \%$. However, the final range of effective MPTT regulation seems to be still acceptable for the proposed low cost solution and this allows to save the significant part of energy inputted to process. It has to be emphasized that energetic yield which occurred by the proposed evolutionary optimization should be even bigger for numerous sections of the thermovoltaic panel with strings managed by individual DC/DC converters. This is the key feature that makes it possible to operate properly for temperature profile of particular TE devices and it may be promising for systems with TEG converters constructed as a stack of devices (multistage module) to improve the coefficient of performance [36] or for the other ones when thermal flux has a tendency towards variations caused by specific exothermic source or when temperature decomposition is non-uniform.

Table 1. The average levels of voltages and load powers comparison.

\begin{tabular}{|c|c|c|c|c|c|}
\hline \multirow{2}{*}{$\begin{array}{l}\text { Load Resistance } \\
\qquad R_{o}[\Omega]\end{array}$} & \multicolumn{2}{|c|}{ With Evolutionary MPPT } & \multicolumn{2}{|c|}{$\begin{array}{l}\text { Without } \\
\text { MPPT }\end{array}$} & \multirow{2}{*}{$\begin{array}{c}\text { Electric Power } \\
\text { Generated } \\
\text { Enhancement }{ }^{1} \\
\eta[\%]\end{array}$} \\
\hline & $\begin{array}{c}\text { Average Load } \\
\text { Voltage } \\
U_{\text {out }}[\mathrm{V}]\end{array}$ & $\begin{array}{c}\text { Average Power } \\
\text { Generated } \\
P_{o}[\mathrm{~mW}]\end{array}$ & $\begin{array}{c}\text { Average Load } \\
\text { Voltage } \\
U_{\text {out }}[\mathrm{V}]\end{array}$ & $\begin{array}{c}\text { Average Power } \\
\text { Generated } \\
P_{o}[\mathrm{~mW}]\end{array}$ & \\
\hline 50 & 1.87 & 69.94 & 1.26 & 31.75 & 120.28 \\
\hline 100 & 2.90 & 84.1 & 1.88 & 35.34 & 137.97 \\
\hline 200 & 3.58 & 64.08 & 2.60 & 33.08 & 93.71 \\
\hline 500 & 4.11 & 33.78 & 3.66 & 26.79 & 26.10 \\
\hline
\end{tabular}

${ }^{1}$ Relative increase in electric power obtained.

Figure 11 shows oscillograms of collector voltage of transistor T1 from boost converter (Figure 7) and PWM control signal measured for self-oscillating circuit: without control (with recording time base $40 \mu \mathrm{s}$ ) as well as for PWMs determined for cases $R_{o}=100 \Omega$, $R_{o}=200 \Omega$ and $R_{o}=500 \Omega$ (with time base $200 \mu \mathrm{s}$ ). As may be interpreted, the local boost converter oscillations frequency is near to $60 \mathrm{kHz}$ and mainly this is defined by the used transformer inductances. The boost converter oscillator wakes up for input voltage near to minimal polarization level $0.7 \mathrm{~V}$ of semiconductor junction and the non-isolated version of applied topology assures that electric current generated below this threshold is transferred to load, too (i.e., after forward polarization of output Schottky diode). For measurement form Figure 11a, the control signal $x_{c 1}(t)$ is on low state all the time and this means M1 transistor switch-off and permanent oscillations. The next three oscillograms illustrate the properness regulation of PWM waveform. As was expected, for the $R_{o}$ close to the optimal $R_{M P P T}$ point this square signal has minimal coefficient of duty cycle and proportionally larger ones for the next two operational points. This regulation tendency is correct and proves the capability of MPP tracking, especially for loads with resistances above the currently optimal one, i.e., when voltage boost operation was successfully applied to MPP correction purpose. 


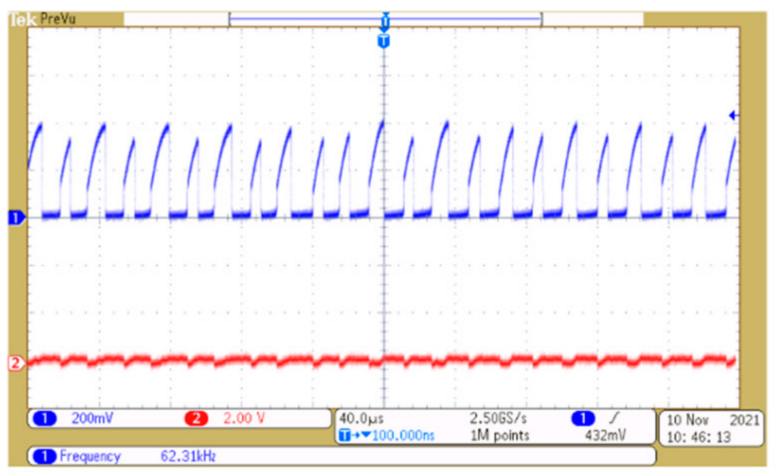

(a)

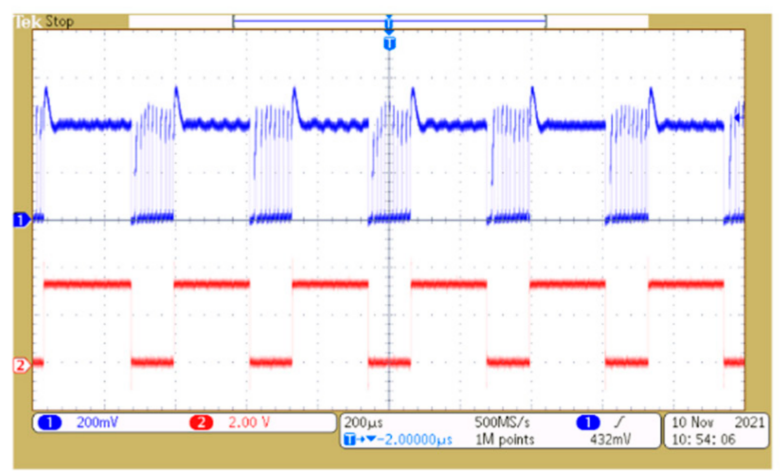

(c)

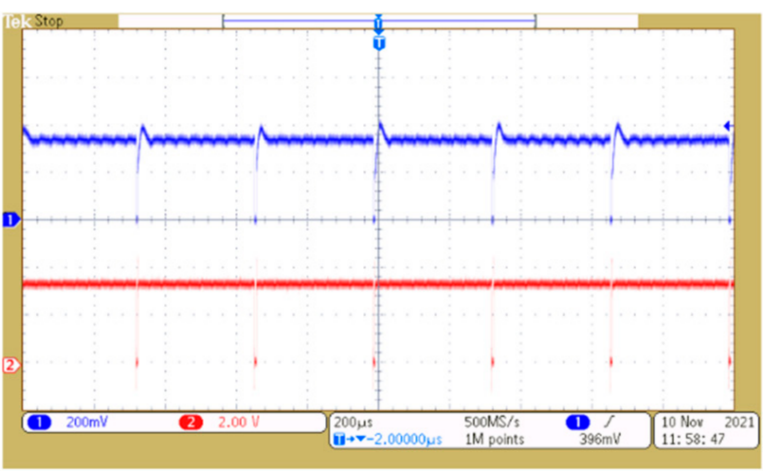

(b)

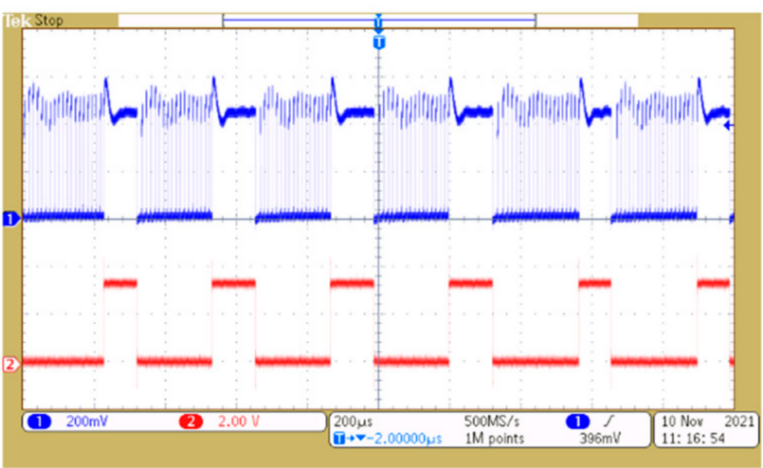

(d)

Figure 11. The DC/DC converter voltage oscillograms measured on collector of switching transistor and on gate of control transistor for PWM signal: (a) disabled, (b) for $R_{o}=100 \Omega$, (c) $R_{o}=200 \Omega$, (d) $R_{o}=500 \Omega$.

The last Figure 12 allows the evaluation of the general usefulness of used TES1-24106 modules for the energy transformation process. They present unsteady state of temperature decomposition between ceramic sides of the device so that gradient $\Delta T$ reached about twice that established during the previous experiment. The measurements presented are observed for load $R_{o}=50 \Omega$ and for point reached after $100 \mathrm{~s}$ voltage $U_{\text {out }}=3.83 \mathrm{~V}$ was measured, which doubled the level of the respective one from Table 1 . This result confirms the linear relationship between TE terminals voltage and temperatures plates difference. The output power reached for $\Delta T \approx 24{ }^{\circ} \mathrm{C}$ is equal to $P_{o}=293.38 \mathrm{~mW}$ that may be $N$-th time multiplied in sectional panel from Figure 7.
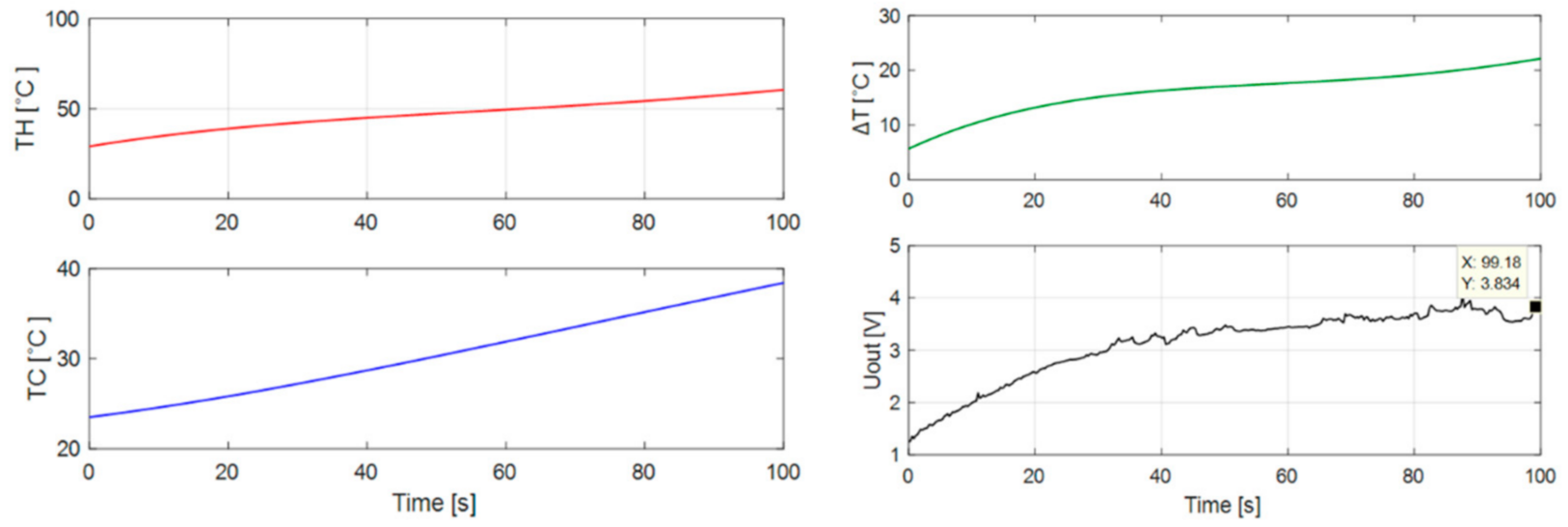

Figure 12. The temperatures and DC/DC converter output voltage curves recorded during $100 \mathrm{~s}$ of thermic unsteady state for resistive load $R_{o}=50 \Omega$. 
This generated energy level is enough for the local oscillator and ultra-low power microcontroller (less than of power $25 \mathrm{~mW}$ consumption during run, full processing state of the used device STM32L4) supplying during the TE panel remote, MPPT self-regulated operation. The constructed panel may be easily extended up to $N=20$ strings controlled individually from one microcontroller, so for beneficial thermal conditions its power supply takes only a small margin of electric energy generated. As was mentioned, non-isolated topology of applied simple DC/DC converter (Figure 7) allows to transfer low electric power to load even below oscillation threshold too, i.e., under undesired temperature conditions and this circuit assures autonomous start of boost operation just after respective power occurrence. Additionally, evolutionary management of electric energy generated $[37,38]$ may be considered for the future enhancement of panel too, and this should be very helpful to optimize power supplying distribution between the active cooling system and output load. The implementation of this modification to evolutionary optimization system is reasonable and could additionally increase the efficiency of electric energy harvesting.

\section{Conclusions}

This work describes an evolutionary MPPT method dedicated to the thermoelectric panel of multi-string sections of low voltage devices connected in series. The simple boost, self-oscillating converters are dedicated to the specific sections, have outputs configured in parallel, and they are controlled by a common central unit equipped with ultra-low power microcontroller. Firstly, details of the proposed evolutionary MPPT regulation technique were explained and it was compared to the popular $\mathrm{P} \& \mathrm{O}$ and INC ones. The results obtained confirm that the proposed solution allows to track optimal operational power point of TE strings much faster than the referenced ones. Convergence speed of the designed algorithm was proved by means of simulations made for ten Thevenin, twoconnector equivalent circuits which model different individual internal parasitic resistances present in real thermoelements. Matching was assured by a boost converters PWM signals optimization. Secondly, the practical experiment effects are presented, for which the panel with the string of sixteen thermoelements passively cooled is tested. The proposed MPPT evolutionary method was implemented to the ultra-low power ARM microcontroller and used for the optimization of the thermal to electric transformation process. The measurements obtained for different representative resistive loads proved the usefulness of the evolutionary optimizations. Future studies on the proposed solution are desirable and, for example, a low power active cooling dedicated method may be applied to improve the efficiency of electric energy generating process.

Funding: This work was supported by the Polish Ministry of Science and Higher Education funding for statutory activities on Silesian University of Technology (BK-246/RAu-11/2022).

Institutional Review Board Statement: Not applicable.

Informed Consent Statement: Not applicable.

Data Availability Statement: Simulation data and practical measurements were saved to files with formats compatible with the software and hardware environment used during the described research performed by the author.

Conflicts of Interest: The author declares no conflict of interest.

\section{References}

1. Kumar, P.M.; Jagadeesh-Babu, V.; Subramanian, A.; Bandla, A.; Thakor, N.; Ramakrishna, S.; Wei, H. The Design of a Thermoelectric Generator and Its Medical Applications. Designs 2019, 3, 22. [CrossRef]

2. Gljuscic, P.; Zelenika, S.; Kamenar, E. Characterisation of Performances of Thermoelectric Generators for Energy Harvesting Applications. In Proceedings of the 29th International DAAAM Symposium, Zadar, Croatia, 24-27 October 2018; pp. 0025-0030. [CrossRef]

3. Ibrahim, M.N.; Rezk, H.; Al-Dahifallah, M.; Sergeant, P. Hybrid Photovoltaic-Thermoelectric Generator Powered Synchronous Reluctance Motor for Pumping Applications. IEEE Access 2019, 7, 146979. [CrossRef] 
4. Wojciechowski, K.; Mierkisz, J.; Fuc, P.; Tomankiewicz, J.; Zybala, R.; Leszczyński, J.; Lijewski, P.; Nieroda, P. Prototypical thermoelectric generator for waste heat conversion from combustion engines. Combust. Engines 2013, 154, 60. [CrossRef]

5. Burnete, N.V.; Mariasiu, F.; Moldovanu, D.; Depcik, C. Simulink Model of a Thermoelectric Generator for Vehicle Waste Heat Recovery. Appl. Sci. 2021, 11, 1340. [CrossRef]

6. Rohit, G.; Manaswini, D.; Kotebavi, V.; Nagaraja, S.R. Performance study of thermo-electric generator. In Proceedings of the International Conference on Functional Materials, Characterization, Solid State Physics, Power, Thermal and Combustion Energy, India, Eluru, 7-8 April 2017. [CrossRef]

7. Kewen Li, K.; Garrison, G.; Zhu, Y.; Horne, R.; Petty, S. Cost Estimation of Thermoelectric Generators. In Proceedings of the 46th Workshop on Geothermal Reservoir Engineering Stanford University, Stanford, CA, USA, 15-17 February 2021.

8. Wang, Y.; Liu, W.; Fan, A.; Li, P. Performance comparison between series-connected and parallel-connected thermo-electric generator systems. Appl. Mech. Mater. 2013, 325, 327. [CrossRef]

9. Kisman, H.M.; Yudistirani, S.A.; Ramadhan, A.I. Analysis of Power Characteristics of Model Thermoelectric Generator (TEG) Small Modular. Int. J. Sci. Technol. Res. 2017, 6, 161.

10. Mrozek, M.; Majcher, A. Application of thermoelectric generators for electrical energy production with a low-temperature heating source. J. Mach. Constr. Maint. 2017, 107, 123-130.

11. Baranowski, L.L.; Snyder, J.; Toberer, E. Concentrated solar thermoelectric generators. Energy Environ. Sci. 2012, 5, 9055. [CrossRef]

12. Olsen, M.L.; Warren, E.L.; Parilla, P.A.; Toberer, E.S.; Kennedy, C.E.; Snyder, G.J.; Firdosy, S.A.; Nesmith, B.; Zakutayev, A.; Goodrich, A.; et al. A high-temperature, high-efficiency solar thermoelectric generator prototype. Energy Procedia 2014, $49,1460$. [CrossRef]

13. Amit, P.; Naruttam, R.; Hemanshu, P. MPPT Methods for Solar PV Systems: A Critical Review Based on Tracking Nature IET Renew. Power Gener. 2019, 13, 1615. [CrossRef]

14. Mnati, M.J.; Abed, J.K.; Araujo, V.G.M.; Bossche, A.V. Review Different Types of MPPT Techniques for Photovoltaic Systems. In Proceedings of the International Conference on Sustainable Energy and Environment Sensing, Cambridge, UK, 18-19 June 2018; pp. 1-6.

15. Dolara, A.; Grimaccia, F.; Mussetta, M.; Ogliari, E.; Leva, S. An Evolutionary-Based MPPT Algorithm for Photovoltaic Systems under Dynamic Partial Shading. Appl. Sci. 2018, 8, 558. [CrossRef]

16. Tey, K.S.; Mekhilef, S.; Seyedmahmoudian, M.; Horan, B.; Oo, A.T.; Stojcevski, A. Improved Differential Evolution-Based MPPT Algorithm Using SEPIC for PV Systems Under Partial Shading Conditions and Load Variation. IEEE Trans. Ind. Inform. 2018, 14, 4322-4333. [CrossRef]

17. Liu, C.; Chen, P.; Li, K. A 500 W low-temperature thermoelectric generator: Design and experimental study. Int. J. Hydrog. Energy 2014, 39, 15497. [CrossRef]

18. Dziurdzia, P. Modeling and Simulation of Thermoelectric Energy Harvesting Processes. In Sustainable Energy Harvesting Technologies-Past, Present and Future; Tan, Y.K., Ed.; InTech: London, UK, 2011; pp. 109-128. [CrossRef]

19. Jouhara, H.; Zabnienska-Gora, A.; Khordehgah, N.; Doraghi, Q.; Les Norman, L.A.; Axcell, B.; Wrobel, L.; Dai, S. Thermoelectricgenerator (TEG) technologies and applications. Int. J. Thermofluids 2021, 9, 100063. [CrossRef]

20. LeBlanc, S.; Yee, S.; Scullin, M.; Dames, C.; Goodson, K. Material and manufacturing cost considerations for thermoelectrics. Renew. Sustain. Energy Rev. 2014, 32, 313-327. [CrossRef]

21. Ramos-Castañeda, C.F.; Olivares-Robles, M.A.; Méndez-Méndez, J.V. Analysis of the Performance of a Solar Thermoelectric Generator for Variable Leg Geometry with Nanofluid Cooling. Processes 2021, 9, 1352. [CrossRef]

22. Polozinea, A.; Sirotinskayab, S.; Schaeffera, S. History of Development of Thermoelectric Materials for Electric Power Generation and Criteria of their Quality. Mater. Res. 2014, 17, 1260. [CrossRef]

23. Ghosh, S.; Mahendran, V. Incremental Conductance MPPT Method for Photovoltaic System. Int. J. Eng. Res. Appl. 2013, 3, 2363.

24. Shang, L.; Guo, H.; Zhu, W. An improved MPPT control strategy based on incremental conductance algorithm. Prot. Control Mod. Power Syst. 2020, 5, 14. [CrossRef]

25. Tan, B.; Ke, X.; Tang, D.; Yin, S. Improved Perturb and Observation Method Based on Support Vector Regression. Energies 2019, 12, 1151. [CrossRef]

26. Telbany, M.E.; Youssef, A.; Zekry, A.A. Intelligent techniques for MPPT control in photovoltaic systems: A comprehensive review. In Proceedings of the 4th International Conference IEEE on Artificial Intelligence with Applications in Engineering and Technology, Kota Kinabalu, Malaysia, 3-5 December 2014; pp. 17-22. [CrossRef]

27. Kottas, T.L.; Boutalis, Y.S.; Karlis, A.D. New Maximum Power Point Tracker for PV Arrays Using Fuzzy Controller in Close Cooperation with Fuzzy Cognitive Network. IEEE Trans. Energy Conv. 2006, 21, 793. [CrossRef]

28. Vidal, A.A.; Tavares, V.G.; Príncipe, J.C. An Adaptive Signal Processing Framework for PV Power Maximization. Circuits Syst. Signal Process 2015, 34, 2973. [CrossRef]

29. Goldberg, D.E. Genetic Algorithms in Search/Optimization and Machine Learning; Addison Wesley: Reading, MA, USA, 1989.

30. Golonek, T.; Chruszczyk, L. Analog circuits specification driven testing by means of digital stream and non-linear estimation model optimized evolutionarily. Bull. Polish Acad. Sci. Technical. Sci. 2020, 68, 1283. [CrossRef]

31. Golonek, T.; Machniewski, J. Analog Circuit Specification Testing by Means of Walsh-Hadamard Transform and Multiple Regression Supported by Evolutionary Computations. Circuits Syst. Signal Process 2018, 37, 2736-2771. [CrossRef] 
32. Golonek, T.; Grzechca, D.; Rutkowski, J. Application of genetic programming to edge detector design. In Proceedings of the International Symposium on Circuits and Systems, Island of Kos, Greece, 21-24 May 2006; pp. 4683-4686. [CrossRef]

33. David, A.P. Thermoelectric Generator: Mobile Device Charger. In Proceedings of the 8th CEBU International Conference on Recent Trends in Engineering and Technology, Cebu, Philippines, 21-22 September 2017; pp. 7-11. [CrossRef]

34. Adami, S.; Marian, V.; Degrenne, N.; Vollaire, C.; Allard, B.; Costa, F. Self-Powered Ultra-low Power DC-DC Converter for RF Energy Harvesting. In Proceedings of the IEEE Faible Tension Faible Consommation Conference, Paris, France, 6-8 June 2012. [CrossRef]

35. Grgic, D.; Ungan, T.; Kostic, M.; Reindl, L.M. Ultra-low input voltage DC-DC converter for micro energy harvesting. In Proceedings of the 9th International Workshop on Micro and Nanotechnology for Power Generation and Energy Conversion Applications, PowerMeMs, Washington DC, USA, 1-4 December 2009; pp. 265-268.

36. Riffat, M.A.; Ma, X. Improving the coefficient of performance of thermoelectric cooling systems: A review. Int. J. Energy Res. 2004, 28, 753. [CrossRef]

37. García Vera, Y.E.; Dufo-López, R.; Bernal-Agustín, J.L. Energy Management in Microgrids with Renewable Energy Sources: A Literature Review. Appl. Sci. 2019, 9, 3854. [CrossRef]

38. Ali, S.; Zheng, Z.; Aillerie, M.; Sawicki, J.-P.; Péra, M.-C.; Hissel, D. A Review of DC Microgrid Energy Management Systems Dedicated to Residential Applications. Energies 2021, 14, 4308. [CrossRef] 